\title{
Ficcionalización
}

\section{novelesca de la guerra civil en la historia} \section{reciente: itinerarios de} un desvío heurístico

\section{Jérôme Cholvy}

jcholvy@libero.it

Resumen: Los conflictos internos son por su naturaleza muy complejos y se prestan con dificultad al análisis historiográfico. A través del estudio de tres novelas emblemáticas sobre tres episodios recientes de conflictos internos, el objetivo del presente trabajo es demostrar que la ficción en la novela puede presentarse como una herramienta de investigación o una clave interpretativa pertinente y tal vez fundamental para la comprensión de estos conflictos. Sin sustituir al análisis historiográfico, la ficción permite, por sus estrategias narrativas y sus mecanismos cognitivos, iluminar, en el caso de los conflictos internos, algunas verdades que guardan con la historia una complementariedad muy fecunda.

Palabras clave: Historia contemporánea y ficción, conflictos internos, mecanismos cognitivos de la ficción

Abstract: Internal conflicts are by nature very complex and make historiographical study challenging. By way of studying three representative novels based on three recent internal conflicts, this exercise aims to demonstrate that fiction could present itself as an investigative tool or a pertinent interpretative key. Thus, it could be fundamental towards understanding said conflicts. Without replacing historiographic interpretation, fiction reveals - thanks to its narrative strategies and cognitive mechanisms - some truths hidden within said internal conflicts; truths which share with historigraphy a productive complementarity.

Keywords: Contemporary history and fiction, internal conflicts, fiction cognitive mechanisms 
JÉRÔME CHOLVY

$\mathrm{E}$ l objetivo de este artículo es estudiar la manera en que la ficción novelesca afronta la narración de la guerra civil, a través de tres novelas contemporáneas sobre conflictos que han marcado el final del siglo veinte: el conflicto interno peruano que confrontó al Estado con el movimiento de tendencia ideológica maoísta, Sendero Luminoso (19801992) ; la guerra civil argelina entre el Estado y la esfera de influencias islamistas (19912002); la guerra de Bosnia-Herzegovina que enfrentó en este territorio a las comunidades serbias, croatas y bosniacas como consecuencia del desmembramiento de la ex Yugoslavia (1992-1995).

Como otras guerras civiles, estos tres son conflictos complejos y extremamente violentos, donde, entre otras cosas, abundan las manipulaciones, las mentiras y tantas zonas obscuras que la misma historia oficial en muchos casos parece promover o, en todo caso, no logra o no hace el esfuerzo por esclarecer, ante lo cual la ficción novelesca parece convertirse en una herramienta pertinente tanto para la investigación como para la comprensión. La cuestión es entonces saber cómo la ficción novelesca representa la violencia que ha caracterizado estos conflictos, y en qué medida permite acceder a un grado de comprensión superior de este fenómeno, y a la elaboración de una forma de verdad que transciende las lagunas del conocimiento factual.

Para intentar responder a esta pregunta, vamos a analizar las siguientes tres novelas representativas de los conflictos evocados: Historia de Mayta de Mario Vargas Llosa, por el Perú (Vargas Llosa, 1984); Le Chien d'Ulysse de Salim Bachi (Bachi, 2001) por el conflicto argelino; y Freelander de Miljenko Jergović (Jergović, 2009) por el conflicto bosnio. Este acercamiento histórico y literario nace de una constatación y responde a una ambición. Se constatan similitudes discernibles entre estos conflictos que, aunque muy diferentes en sus orígenes, presentan, sin embargo, similitud en sus dinámicas. El objetivo es dar cuenta al mismo tiempo de la variabilidad y de la convergencia de las estrategias narrativas y de los acercamientos temáticos en el tratamiento ficcional contemporáneo de estas tragedias históricas.

\section{Tres conflictos difíciles de estudiar}

Unas breves observaciones preliminares son necesarias para evidenciar, desde un punto de vista histórico, los puntos comunes que justifican el acercamiento de estos tres conflictos. 
Concentrados en el mismo período, entre 1980 y 2000, los tres conflictos han marcado con su intensidad y su violencia el final del siglo veinte y, a pesar de haber acontecido en áreas geográficas distantes unas de otras y al interior de culturas extranjeras la una para la otra, se parecen mucho. La historiografía, con sus propios instrumentos de análisis, puede proporcionar mucha información precisa, datos, cronologías detalladas de los acontecimientos, pero al final parece encontrarse en problemas en lo que se refiere al sentido que se le debe otorgar a tales explosiones de violencia, así que la cuestión central de las significaciones, implicancias y paradojas de estos conflictos queda a menudo suspendida. La incapacidad de explicar con claridad y de comprender, con la que están confrontados los historiadores parece el denominador común de sus investigaciones. "Comment voir, lire, trouver une cohérence à ce conflit?» ${ }^{1}$ (Stora 2001: 9) se plantea el historiador francés Benjamin Stora en una interrogante que toma la forma de una problemática común a estas tres guerras civiles.

Un estatuto definitorio ambiguo. Desde el punto de vista histórico la noción de guerra civil responde a criterios de definición muy variables. Cada uno de los tres países reserva la denominación "guerra civil" a unos episodios constitutivos de la historia nacional, dejando a menudo indeterminada la naturaleza del conflicto en cuestión. Una batalla de palabras ha rodeado la definición de estos tres conflictos: la violencia de los años ochenta en el Perú, o de los años noventa en Argelia, el periodo del terrorismo, conflicto bosniaco o guerra de los Balcanes, las denominaciones fluctúan, se multiplican y esta "querelle" semántica es reveladora de la dificultad para delimitar los orígenes, la naturaleza y las finalidades de estas guerras.

De la indiferencia a la ceguera. En los tres casos el inicio del conflicto está marcado por una respuesta a un proceso electoral, situación en que la confrontación de grupos antagonistas se pone fuera de los mecanismos democráticos del dialogo, y autoriza de hecho el recurso a la violencia como medio para restablecer el orden, o establecer un nuevo orden. Es el inicio de un engranaje que llevará a estos países a un abismo de violencia. Y en el desarrollo de cada uno de estos conflictos se observa un esquema recurrente que empieza por la indiferencia,

$1 \ll$ ¿Cómo ver, leer, encontrar una coherencia en este conflicto?». Todas las traducciones son personales. 
JÉRÔME CHOLVY

continúa con el ocultamiento de sucesos y desemboca en sangrientas represiones de orden político-militar en un marco de algo así como una ceguera colectiva.

La crisis de la representación. Las dificultades de documentación encontradas por la prensa son reveladoras de una crisis de la representación que daña a la historiografía. Entre sobremediatización, como en el caso del conflicto bosniaco, control de la información, censura o relativo interés mediático internacional, en el caso del conflicto argelino, la documentación obtenida al final es pobre y simplificadora. El historiador Benjamin Stora, frente a esta dificultad consagra un capítulo entero de su obra La guerre invisible. Algérie, années 90 (Stora 2001) a la crisis de representaciones en esta guerra, y formula una interrogante que él mismo extiende al conjunto de los conflictos: «La représentation de cette guerre en Algérie n'est-elle pas inscrite, dans le siècle qui s'ouvre, dans une tendance générale qui va à l'invisibilité des conflits?»² (Stora 2001: 10).

El pavor frente a la espiral aterrorizante de las violencias. La importancia, la intensidad, el horror de las violencias perpetradas son otros de los aspectos puestos en evidencia por la historiografía que ha tocado tanto la sensibilidad de los escritores como la de la opinión pública. Y otro punto sobre el cual persisten incertidumbres y polémicas es el número probado de las víctimas. Eso ha confirmado el casi desconocimiento real de los acontecimientos y la dificultad de dar cuenta de ellos.

Con esta presentación sumaria de los tres conflictos queremos demostrar en qué medida la historiografía revela sus carencias extremas y constatamos que cuando se intenta delimitar la naturaleza de estos conflictos, los prefijos privativos prevalecen: indefinibles en su estatuto, invisibles en su representación, inenarrables en su opacidad, inimaginables en su abominación, tantas limitaciones que no facilitan ni la comprensión histórica ni la explicación científica.

\section{Tres novelas}

Hay que precisar que la elección de solo tres novelas no puede dar cuenta de la variedad de formas novelescas y de acercamientos ficcionales que estos conflictos han generado en

2 «¿La representación de esta guerra de Argelia no está inscrita, en el siglo que se abre, en una tendencia general que va a la invisibilidad de los conflictos? ». 
los diferentes países interesados. Pero consideramos que cada una de estas obras propuestas para el análisis plantea un interesante tratamiento ficcional del conflicto: escapando a las urgencias de la literatura de testimonio y superando la preocupación de autenticidad de los acontecimientos, las tres novelas seleccionadas ponen su relación con el hecho histórico de manera libre. La relación referencial al periodo histórico es floja, tal vez muy tenue, hasta desviada, y ninguna de estas novelas en su peritexto hace directamente alusión a la guerra civil que, sin embargo, sirve de marco temporal e histórico al relato.

Historia de Mayta, de Mario Vargas Llosa (1984), remite de manera muy clara a una reflexión sobre los acontecimientos históricos del momento de su redacción. Para ilustrar este proyecto, la novela toma entonces la forma de una investigación efectuada por un periodista sobre un levantamiento revolucionario fracasado que se desarrolló en los años cincuenta en Jauja, pueblo lejano de la sierra peruana, a instigación de un ex-condiscípulo suyo, Mayta. Según la tesis de este periodista -el narrador principal de la novela- que quiere hacer un relato novelado de este episodio tras haber consultado a varios testigos, este acontecimiento sería el antecedente tanto ínfimo como grotesco del conflicto que devasta el Perú actual del narrador, y del mismo autor. La particularidad narratológica de la novela reside en el recurso permanente a la alternancia de los niveles diegéticos. Como ya lo refiere el título, a un tiempo temático y remático, según la clasificación de Genette (Genette 1991), la narración alterna entre el nivel intradiegético al cual pertenece el narrador principal y el nivel metadiegético de la ficción que él elabora. Existe, sin embargo, un tercer nivel, extradiegético, revelado en la última frase del relato que desvela que este en su totalidad es una ficción: "Y recuerdo, entonces, que hace un año comencé a fabular esta historia mencionando, como la termino, las basuras que van invadiendo los barrios de la capital del Perú» (Vargas Llosa 1984: 346), reorientando así la lectura del texto no solo como la narración constitutiva de una ficción sino como la de una ficción de la ficción.

La trama de ElPerro de Ulises de Salim Bachi (2001) se desarrolla en una temporalidad muy circunscrita y datada: la narración de la jornada del narrador Hocine, empieza en la madrugada del día 29 de junio del 1996 y acaba en la madrugada del día siguiente, con el regreso de Hocine a su casa donde es recibido a golpes de fusil por uno de sus hermanos que lo toma por un terrorista. Aun si el relato no dice claramente si ese tiroteo le es fatal a Hocine, todo deja suponer que lo es. Entre estos dos momentos, la narración ha proliferado en digresiones y extensiones en forma de metarelato y de analepsis. La historia individual de 
JÉRÔME CHOLVY

Hocine es así superada para englobar la de la Argelia de los años noventa a través del destino de los personajes que gravitan alrededor del héroe, mientras que este cumple una especie de periplo uliseano a través del dédalo real e imaginario de la ciudad de Cyrtha. La indeterminación del espacio genera un equívoco: la ciudad de Cyrtha es espacio novelesco, en parte real porque se inspira en la ciudad de Constantina donde nació el autor, pero también ficticio porque resulta de una tradición mítica y mitológica. Cyrtha es así una alegoría de la Argelia y de su historia, que ella condensa en sus callecitas laberínticas.

Freelander (2007), en relación a las dos otras novelas que tomamos en cuenta, presenta una estructura narrativa más sencilla y lineal a cargo del personaje principal, el profesor de historia jubilado Karlo Adum que acaba de recibir en Zagreb un telegrama que le informa del deceso de un viejo tío que vive en Sarajevo y de quien se había olvidado. El testamento dejado por su tío le sirve entonces de pretexto para emprender un viaje a través de Croacia y de Bosnia, hacia su ciudad de origen. En su itinerario, que evoca -también- el periplo uliseano, se cruzará con unos personajes que no logran superar los traumas de la historia reciente, razón y oportunidad suficiente ésta para una constatación de las consecuencias materiales, sociales y psicológicas del conflicto y para una reflexión sobre su origen. Este viaje funciona como una metáfora de otro viaje efectuado en paralelo a lo largo del camino hacia Sarajevo, que recorre la historia yugoslava del siglo veinte revivida a través de la memoria del viejo profesor de historia que se pone como testigo.

\section{Marcas patentes y trazas latentes del conflicto}

\subsection{La violencia como catalizador de la Historia nacional}

En los tres países donde se desarrollan las novelas, la guerra civil se impone con su cortejo de violencia como una constante histórica en los cimientos de la nación.

De las tres novelas, El Perro de Ulises es la que subraya más esta constante histórica, por la imagen de la Cyrtha antigua que se superpone a la ciudad moderna en la memoria de Hocine. La relación que Hocine mantiene con esta imagen funciona como una reminiscencia de las violencias pasadas que han caracterizado el destino de la ciudad y que la barbarie del presente repite ahora al infinito (incluso la guerra de independencia argelina de quien la guerra corriente parece la repetición macabra).

En Freelander, las numerosas analepsis, que originan la evocación de la infancia de Karlo Adum en Sarajevo durante la Segunda Guerra Mundial, constituyen los principales indicios de 
que la violencia es el hilo conductor en el panorama histórico bosniaco. En el territorio y en la historia que Karlo Adum atraviesa, las consecuencias de las violencias pasadas son perceptibles en todo su recorrido, fundidas en el ambiente como en la memoria. Así la significación del símbolo de la calavera en estas tierras supera su portada semántica habitual y se hace cargo de un paroxismo indicativo del culto casi cultural por la violencia transformada en verdadero valor identitario.

En las novelas de Mario Vargas Llosa, la referencia a la violencia histórica es frecuente, pero en Historia de Mayta el tratamiento de este tema tiene una originalidad por el hecho de que no está en la exploración del pasado sino en la anticipación apocalíptica. La historia de Mayta sería en efecto el episodio precursor de la situación interior desastrosa descrita por el narrador al momento de su investigación:

¿Por qué Mayta? Si de él no se acuerda nadie. En efecto ¿por qué? ¿Porque su caso fue el primero de una serie que marcaría una época? ¿Porque fue el más absurdo? ¿Porque fue el más trágico? ¿Porque, en su absurdidad y tragedia, fue premonitorio? ¿O, simplemente, porque su persona y su historia tienen para mí algo invenciblemente conmovedor, algo que, por encima de sus implicaciones políticas y morales, es como una radiografía de la infelicidad peruana? (Vargas Llosa 1984: 8)

La permanencia de la violencia a escala histórica es claramente explicitada en la ocasión de la visita del narrador al museo de la Inquisición: «Condensada en unas cuantas imágenes y objetos efectistas, hay en él un ingrediente esencial, invariable, de la historia de este país, desde sus tiempos más remotos: la violencia. [...] Es bueno venir aquí, a este Museo, para comprobar cómo hemos llegado hasta lo que somos hoy, por qué estamos como estamos» (Vargas Losa 1984: 52).

Constante dramática ineludible, la violencia toma así a través de la escritura un corte trágico. Fatalidad cuyos estragos ineluctables resurgen por alternancia con el destino histórico de estas tres naciones y parecen condenar a sus habitantes a una eternidad de sufrimiento. En este marco los tres conflictos abarcados por las tres novelas no serían entonces más que las últimas manifestaciones de esta violencia cíclica.

\subsection{El silencio solapado de la violencia}

Pero, aunque presente en diferentes niveles históricos, los actos de violencia estrictamente vinculados con los conflictos tratados en las tres novelas, parecen evacuados del campo de la 
JÉRÔME CHOLVY

ficción. Muy pocas son, en cada uno de los tres relatos, las alusiones al horror de la violencia perpetrada en estos conflictos. Volvemos aquí a citar el historiador Benjamin Stora, que a propósito del conflicto argeliano escribe: «Mais, dans les représentations de cette tragédie, se devine également toute l'impossibilité à montrer vraiment cette guerre. Les dizaines de films de fiction, d'ouvrages «romanesques» ne sont d'ailleurs pas des œuvres de guerre. Au cinéma, le plus étrange [...] est la distance prise avec la représentation de la violence». ${ }^{3}$ (Stora 2001: 113)

Este silencio corresponde entonces a una intención que se debe interpretar. La ausencia de representaciones directas de la violencia cometida parece remitir a la experiencia vivida al momento de los conflictos, para los cuales censura, manipulación, desinformación han contribuido al obscurecimiento mediático. La difícil investigación llevada por el periodista narrador de Historia de Mayta constituye una perfecta ilustración, y la guerra civil aparece solo en el fondo: siempre palpable, nunca es visible y la crueldad del conflicto nunca es propiamente representada.

La representación de la violencia está ausente también en Freelander. En la novela no se encuentra ninguna mención explícita de los crímenes de guerra, de los que subsisten solo trazas anecdóticas aunque indelebles en el paisaje y en la memoria. Igual constatamos en El Perro de Ulises, con la sola excepción de una escena de tortura detallada con un tono neutro de manual. Es la única incursión en el horror de la violencia que aparece así distanciada, hasta exorcizada, por la neutralidad del tono usado.

Los tres escritores se detienen entonces ante la representación de la violencia que parece oponer una barrera ética. La ficción utilizará otras modalidades de representación para aludir a esta violencia irrepresentable e indecible al punto de volverse inimaginable. Esto se logra principalmente a través de los efectos de su contaminación en la vida de los personajes y del efecto deletéreo en las relaciones sociales que su existencia obsesiva es perceptible. Inscrita en la vida de los personajes, la violencia aparece más explorada bajo la modalidad personal que en la vertiente colectiva: el sufrimiento íntimo parece el reflejo atenuado de los dramas históricos.

En Freelander, por ejemplo, la partida de Karlo Adum de Sarajevo es originada por haberle causado la muerte accidental a uno de sus compañeros de colegio, de quien

$3 \ll$ «n la representación de esta tragedia, se adivina igualmente toda la imposibilidad de mostrar verdaderamente esta guerra. Las docenas de películas de ficción, de obras "novelescas" no son obras de guerra. Al cine, lo más extraño [...], es la distancia tomada con la representación de la violencia ». 
soportaba humillaciones. Este evento aparentemente casual nos indica bien la posición central de la violencia en el destino del profesor, como una fatalidad inevitable con la que se conforma por necesidad. Y el tema es central aun en la historia familiar de Karlo, cuyo padre había sufrido una grave agresión por parte de su propio hermano, ilustración esta, en un plano íntimo, de la violencia fratricida perpetrada en el país. Toda la vida profesional del personaje está salpicada de tensiones identitarias latentes en la sociedad yugoslava, y donde se puede identificar el origen del conflicto bosnio. Estas tensiones, que suben a la superficie en la mínima ocasión en las relaciones sociales, dan a la violencia una expresión perceptible en el resentimiento que perdura en las relaciones entre las comunidades, basadas en el recelo recíproco y la hostilidad instintiva. El relato en su globalidad está caracterizado por el miedo del otro y un sentimiento difuso de inseguridad.

El recelo es también el hilo conductor en las entrevistas del narrador de Historia de Mayta, y un clima de inseguridad y de delación acompaña siempre al narrador a lo largo de su investigación y se manifiesta de manera más fuerte en Jauja, en los lugares de la insurrección pasada y presente. La veracidad de los testimonios recordados no está nunca garantizada y se muestra así una sociedad en la cual, bajo el efecto de la violencia, valores como la certidumbre, la sinceridad o la confianza, ya no son actuales.

En El Perro de Ulises, son los diálogos y las relaciones entre los personajes los que, impregnados de una agresividad mal disimulada, atestiguan el clima de violencia que ha contaminado cualquiera relación social, desde la esfera familiar: pensamos en los duros intercambios entre el narrador y su madre, la falta de armonía entre hermanos, hasta la dura acogida del narrador por parte de sus familiares cuando regresa víctima del tiroteo. La violencia ha contaminado el tejido familiar y se ha infiltrado en la vida de todos.

\section{Miradas sobre el presente y escapatorias}

\subsection{La decadencia como escenario}

Si una de las características ineludibles de los conflictos, la violencia efectiva, se escapa de la mirada de todos y se expresa con modalidades desviadas, las consecuencias de las guerras civiles están presentes en los relatos y generan una evocación que alumbra ciertos aspectos comunes a los tres acercamientos ficcionales, y nos informan sobre la manera con que condicionan la comprensión de los conflictos de parte de los personajes. 
JÉRÔME CHOLVY

La mención frecuente y compartida por las tres novelas de la temática de la basura invasora y de la ruina del ambiente, la insistencia de los autores sobre esta característica del marco de la ficción, devela una intención precisa, porque es ésta la imagen terrible de la realidad a la que los relatos nos remiten. La más elocuente explotación del tema se encuentra en la novela de Vargas Llosa que se abre y se termina con la alusión a la basura. La invasión de la ciudad por la basura es así en esta novela el corolario de la miseria crecente, y materializa la imagen de la catástrofe hacia la cual corre el país bajo el efecto de la guerra civil.

La Bosnia que observa Karlo Adum a través de la ventana de su carro parece más un país bajo la ruina que sumergido en los desechos. Conjugadas con los cementerios y los campos de minas, las ruinas constituyen lo esencial del paisaje que recorre el personaje, haciendo de la muerte y de la destrucción los elementos preeminentes de un escenario postapocalíptico donde toda traza de vida parece borrada. A un nivel interpretativo superior, la propagación de la basura y la predominancia de la ruina en el marco puesto en escena por la ficción son el reflejo metafórico de una infección más grave en el cuerpo social: aquella de la perversión de los valores.

La peste evocada por Mourad en El Perro de Ulises al respecto del fanatismo islamista parece corroborar esta idea, y se va a juntar con los otros indicios latentes de la violencia que ya hemos evocado, como el recelo y la agresividad en las relaciones sociales. Pero a todo eso hay que añadir otros estigmas directamente derivados del conflicto: uno de las más preocupantes, la corrupción.

Gangrena de una sociedad en decadencia, este mal se combina al más alto grado con la imagen corroída de la realidad prefigurada en las tres novelas. En Historia de Mayta el senador Campos es un ejemplo de la decadencia de los valores, principalmente de la lealtad política y de la integridad moral. Sin embargo, es el destino mismo de Mayta que ilustra mejor la decadencia moral consecutiva al conflicto con el paso del ideal revolucionario al banditismo, y en el final de su historia lo vemos implicado en asaltos de bancos y en raptos.

\subsection{Estrategias de escape saludables}

La realidad así evocada es tan insoportable que el narrador y los personajes parecen adoptar frente a ella estrategias de escape, fundamentales porque les permiten sobrevivir en escenarios semejantes y, sobre todo, no confundirse con ellos. Tomando escapatorias y vías preparadas por el imaginario, ellos encuentran efectivamente el medio para resistir la desolación de lo 
cotidiano y para afirmar así su parte de humanidad. Perfectamente conscientes del horror que los rodea e intenta aplastarlos, buscan a través de la imaginación razones para tener esperanzas y la fuerza para seguir viviendo, elaborando precarios amparos personales contra la barbarie generalizada.

La narración del viaje de Karlo Adum progresa por la digresión onírica a partir de anotaciones sobre el ambiente y los acontecimientos. El texto, que no presenta rupturas formales ni partes, refleja perfectamente la idea de la continuidad del viaje que se desarrolla en paralelo con el flujo de la memoria. Este movimiento determina para el ensueño una posición capital en la comprensión del presente, poniendo al profesor en una suerte de zona neutra que lo protege de la brutalidad de los signos del conflicto proponiendo soluciones de repliegue interior, aunque presenta, con la repetición de las secuelas, lamentablemente, el paso de la eternidad.

La imaginación constituye un refugio saludable en El Perro de Ulises, donde los recursos de la conciencia del narrador al mito de Cyrtha, antes representación de un destino histórico del cual no se puede escapar, responden a una necesidad vital de liberarse del peso de la realidad, como lo testimonia la toma de conciencia final de Hocine: «J'inventais Cyrtha pour me sauver. Cruel paradoxe ${ }^{4}$ (Bachi 2001: 227).

En la novela de Vargas Llosa, la ficción literaria se inscribe en un acercamiento a la realidad expresamente reivindicado por el narrador. La elección de este enfoque parece demostrar una vez más toda la importancia de la libertad concedida por la imagincación, verdadero espacio salvador de reconfiguración de la realidad, que preserva del riesgo de atonía desesperada que la concentración en el horror de la actualidad puede llevar. Así, la constatación de la desolación de las barriadas hace revisar el interés mismo de su proyecto y hace vacilar su fe en la literatura antes de proclamar los beneficios personales y colectivos: «Si, como el Padre canadiense del cuento de Mayta, yo también me dejo ganar por la desesperación, no escribiré esta novela. Eso no habrá ayudado a nadie; por efímera que sea, una novela es algo, en tanto que la desesperación no es nada» (Vargas Llosa 1984: 38).

Es la motivación profunda de esta intención y el enfoque de la ficción firmemente reivindicado que le corresponde, las que marcan el punto de vista de la parte final de nuestra reflexión, porque es precisamente el escape por lo imaginario, reflejo del desvío por la ficción, lo que va a permitir comprender mejor estos conflictos considerados ilegibles

4 «Yo inventaba Cyrtha para salvarme. Cruel paradoja». 
JÉRÔME CHOLVY

e indescriptibles, llevando un poco de luz a las zonas más obscuras de la Historia. Un mecanismo cognitivo a primera vista paradojal.

\section{De la ficción como proceso cognitivo}

\subsection{La experimentación cognitiva de la ficción}

Es en la obra monumental de Paul Ricœur, Tiempo y narración, que encontramos la idea de que la "puesta en intriga», en el caso del relato histórico como del relato de ficción, tiene una función heurística central: « ella "toma juntos" e integra en una historia total y completa los acontecimientos múltiples y dispersos, y así esquematiza la significación inteligible que se atribuye a la narración tomada como un todo » (Ricoeur 1995: 32).

Este proceso narrativo que la Historia comparte con el relato de ficción, lejos de restarle rigor científico, permite por el contrario, por intermedio de la triple mímesis, arribar a una forma de conocimiento. El círculo de la triple mímesis comporta tres etapas que de la prefiguración pasan a la configuración para desembocar en la refiguración. La función de mediación de la puesta en intriga hacia un horizonte de verdad es entonces fundamental y, en el caso de nuestros relatos de ficción, tomaremos en cuenta principalmente la segunda etapa, la de la configuración.

Las configuraciones originales desarrolladas a esta etapa en las tres novelas son susceptibles de proporcionar unas herramientas heurísticas que pueden ayudar a la comprensión de los conflictos abarcados por los relatos. Primero por las relaciones sintomáticas que cada uno de los relatos mantiene con la noción del "fintar".

En su obra ¿Por qué la ficción?, Jean-Marie Schaeffer (Schaeffer 2003) traza la diferencia entre el fingimiento lúdico y el fingimiento serio. Si el fingimiento lúdico compartido corresponde a la ficción e implica una libre adhesión a sus propias reglas, el fingimiento serio por oposición no es nada más que la mentira, o sea la intención consciente de engañar. Preámbulo importante porque el tema del fingimiento está en el corazón mismo de nuestro corpus, y actúa a un doble nivel: se refiere al estatuto innegable de estas obras y sitúa sin ambigüedad cada texto en el campo de la ficción. Pero el fingimiento funciona igualmente como estrategia narrativa al servicio de una "puesta en abismo" tanto de la Historia (con mayúscula) como de la historia (con minúscula). De hecho, el fingimiento lúdico pone en la escena, y de alguna manera duplica -y tal vez replica, como en el caso de 
Historia de Mayta -a través de elecciones narratológicas, la prevalencia del fingimiento serio que caracteriza estos conflictos.

El mérito principal de esta estrategia ficcional está a nuestro parecer en la modalidad vertiginosa de experimentación de la opacidad que rodea estas guerras y que esta "puesta en intriga” específica del fingimiento permite a cualquier lector de probar. A través de la reactivación de la inmersión mimética por la inmersión ficcional, el lector accede a una modelización ficcional del universo real. Haciendo funcionar nuestras facultades de la misma manera en un marco ficticio como en lo real, la inmersión ficcional autoriza entonces la experimentación cognitiva de "universos de la ficción", que aún si pertenecen al campo de lo posible mantienen también fecundas relaciones heurísticas con lo real. La ficción literaria se vuelve entonces en un laboratorio donde los posibles son experimentados, ocasión de hacer ficcionalmente una experiencia de la realidad -resumiendo la teoría de los "mundos posibles" desarrollada por Thomas Pavel (Pavel 1995).

\subsection{Cuando el fingimiento lúdico pone en escena el fingimiento serio}

Ya hemos subrayado en qué medida el fingimiento serio, la mentira, es una constante temática que hace eco en las novelas a las manipulaciones puestas en evidencia por la historiografía en la vertiente histórica. Ponemos ahora que el fingimiento, en su variante lúdica, sea la ficción, y que en su perspectiva configurante nos devele algún sentido profundo de estos conflictos.

En varios momentos de su viaje, Karlo Adum se topa con la ficción bajo la forma de quioscos de DVD pirateados. Es esta, junto con las ruinas, la primera imagen de la Bosnia que nos aparece en el relato y a continuación el profesor cruzará varios de estos quioscos en su recorrido. La presencia de este elemento parece constantemente inscribir su progresar en un espacio de ficción como si este régimen fuera la única modalidad apta para comprender lo real y por extensión el conflicto. La recurrencia de sueños premonitorios y la frecuencia de las analepsis que revisitan episodios de la vida de Karlo Adum contribuyen además fuertemente a este sentimiento de alejamiento ficticio. La novela, por su reivindicación ficcional y sus elecciones configurantes al nivel narrativo, proclamaría entonces a través de su puesta en abismo la revelación de un fenómeno histórico capital: el rechazo del conflicto en un subconsciente imaginario, suerte de pesadilla recurrente, en cierto modo adormecida por la memoria, y de la cual el fingimiento lúdico se encarga de recordar la factibilidad. 


\section{JÉRÔME CHOLVY}

En El Perro de Ulises es el mito, ficción suprema, que tiene una función preponderante en el plano configurante de la narración, y también como vector de percepción sensorial para el narrador. El mito histórico favorece entonces un curioso viraje heurístico, porque permite elucidar cuánto la Historia remite al simulacro, rigiendo la memoria de los personajes, mientras que la ficción deviene apuesta de la verdad. Toda certidumbre es entonces prohibida, negada, y la lectura es, mejor que otro, el lugar de esta vertiginosa experiencia. Una angustiosa verdad aparece en la obscuridad de esta tragedia con el progresar del narrador en la ciudad, así como el de la lectura, es que la verdad absoluta no se puede encontrar: «Où est la vérité? J'avais tout inventé. Menti, du premier au dernier mot» (Bachi 2001: 255).

Esta lección inquietante aparece también en la de Historia de Mayta, donde el recurso de la ficción es asumido como método de trabajo: "Mi obligación es escuchar, observar, cotejar las versiones, amasarlo todo y fantasear» (Vargas Llosa 1984: 59). El mecanismo narratológico proyecta entonces el lector en un engranaje de engaños en el seno del cual toda verdad se escapa sin parar, para hacerle experimentar mejor su dolorosa carencia. La estrategia novelesca, que consiste en plagiar la factibilidad de la investigación biográfica para mejor revelar la parte de ficción, parece que quiere probar que, en esta búsqueda, la verdad no es nada más que una ficción. Una historia en forma de engaño, de la cual la ficción, elevada ahí a verdadera herramienta heurística, se hace oráculo: «Porque soy realista, en mis novelas trato siempre de mentir con conocimiento de causa [...]. Es mi método de trabajo. Y, creo, la única manera de escribir historias a partir de la historia con mayúsculas» (Vargas Llosa 1984: 32).

\section{Conclusión}

Aun tomándose libertades y distancia de la actualidad del acontecimiento histórico, la ficción nos reconduce, pues, siempre con fuerza a él, y tal vez con mayor clarividencia porque, como lo hemos notado, utiliza precisamente el discurso ficcional. Por sus estrategias narrativas y sus mecanismos cognitivos, la ficción permite acceder a verdades experimentadas de otro modo que lo científico de la historiografía, pero que tienen -a pesar de la diferencia de modalidad de comprensión- una complementariedad cognitiva muy fecunda. Los "posibles" de la ficción autorizan en efecto la configuración original de elementos históricos con un valor representacional, a falta de referencial, altamente cognitivo. Pues es precisamente proclamando la emancipación de lo real y valiéndose de 
la libertad de la imaginación, que el novelista deviene en gran ordenador semántico del caos histórico, en un papel de demiurgo -abiertamente asumido en particular por Mario Vargas Llosa- que las tres novelas estudiadas ilustran bien, a través de sus configuraciones narrativas y de sus dispositivos narratológicos.

Sin embargo, es la noción de referencia cruzada desarrollada por Paul Ricoeur que, por asociar en un mismo proceso heurístico historia y ficción, nos parece sintetizar en el mejor modo la ventaja cognitiva representada por su conjunción. Según Ricoeur, la historiografía, y la referencia metafórica, o sea la ficción literaria, permiten conjuntamente la re-figuración (en el sentido de otra y nueva figuración, o re-significación) de la temporalidad humana, o sea de la Historia. De hecho, la Historia re-elabora el pasado como la ficción re-crea el mundo, y el vector de esta experiencia es la narración que, por la facultad de configuración de la "puesta en intriga", desempeña un papel determinante para la construcción del sentido histórico. Ricoeur subraya además como, tanto por una parte como por otra, la re-figuración resulta del trabajo de la imaginación. Las intrigas ficticias funcionan como laboratorios donde podemos experimentar la validez de nuevos esquemas de inteligibilidad del tiempo y de la Historia, de ahí la importancia de apreciar el aporte cognitivo que estas modelizaciones ficcionales presentan por las problemáticas históricas del tipo que nos ha interesado.

Esta tendencia se está verificando con siempre mayor frecuencia en los estudios historiográficos recientes sobre los conflictos en general. Así la cuestión del valor documentario y del estatuto de la ficción es de gran actualidad, por ejemplo, en el estudio de los relatos de guerra y de las persecuciones. Y habré de concluir con la socióloga Nathalie Heinich:

Aussi n'y a-t-il pas lieu de dire ici comme le feraient la morale ordinaire et la déontologie de l'historien, "ce n'est qu'un roman ", en le rejetant hors de la catégorie des témoignages acceptables par le chercheur, c'est justement parce qu'il s'agit d'un roman - et que ce ne pouvait être qu'un roman - qu'il nous faut, plus qu'aucun autre, écouter un tel récit. (Heinich 1998: 47)

5 «Pues no es el caso de decir como lo harían la moral ordinaria y la deontología del historiador, "no es más que una novela”, rechazándola de la categoría de los testimonios aceptables por el investigador, de lo contrario es propiamente porque es una novela -y que no podría ser otra cosa que una novela- que tenemos que escuchar, más que cualquier otro, un tal relato». 


\section{REFERENCIAS}

BACHI, Salim

2001 Le chien d'Ulysse. París: Gallimard.

Genette, Gérard

1991 Ficción y dicción. Barcelona: Lumen.

HeINICH, Nathalie

1998 «Le témoignage entre autobiographie et roman: la place de la fiction dans les récits de déportation». Mots, N. 56, pp. 33-49.

Jergovic, Miljenko

2009 Freelander. Arles: Actes Sud, Coll.

Pavel, Thomas G.

1995 Mundos de ficción. Caracas: Monte Ávila Editores.

Ricoeur, Paul

2004 Tiempo y narración. Configuración del tiempo en el relato histórico. Volumen I. México: Siglo XXI editores.

Schaeffer, Jean-Marie

กิ 2003 ¿Por qué la ficción? Madrid: Lengua de Trapo.

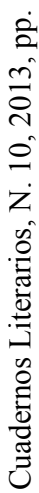

StORA, Benjamin

2001 La guerre invisible. Algérie, années 90. París: La bibliothèque du citoyen. Presses de Sciences Po, Coll.

Vargas Llosa, Mario

1984 Historia de Mayta. Barcelona: Seix Barral. 